\title{
Markers of success of passing the unified state exam
}

\author{
Lubov Gubareva*, Yulia Konygeva \\ North-Caucasus Federal University, Department of Biomedicine and Physiology, 355009 \\ Stavropol, Russian Federation
}

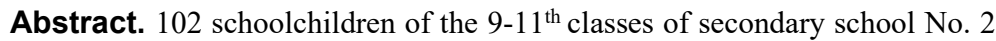
of Stavropol, without genetic pathology, were examined. The functional state of the central nervous system was determined by the method of computer chronoreflexometry; using psychological tests, we determined the level of personality (PA) and situational (SA) anxiety, as well as (and) the level of aggressiveness. It was established that in the 9-11th classes, girls and young women have a higher level of PA and SA than boys and young men $(p<0.05-$ 0.01). During the training the girls' and boys' the level of PA remains relatively constant, however, the variability of PA of 17 years-old young women is higher than of the young men. The level of SA of the girls tends to increase throughout the entire period of study in high school, while for boys it rises only the $10^{\text {th }}$ class, and decreases by the beginning of the $11^{\text {th }}$ class. For the indicators of aggression, gender differences begin to appear in the $10^{\text {th }}$ class: aggressiveness index and indirect aggression in the boys' significantly higher than the girls' are. In the $11^{\text {th }}$ class, young men significantly increase in comparison with girls an indicator of hostility, verbal aggression and offence $(\mathrm{p}<0.05)$.
\end{abstract}

\section{Introduction}

With the introduction of the unified state exam (USE), the health status of Russian students has deteriorated significantly. According to a number of authors, only $10 \%$ of graduates finish school healthy. In this regard, the problem of studying the psychophysiological characteristics of graduates that contribute to the successful passing of the exam or reduce its effectiveness remains relevant. An intermediate step to the USE is the test exams and the main state exam (MSE), which falls on the critical period of human ontogenesis - the period of the final formation of puberty, the formation of functional maturity of the central nervous system, and personality formation. At the same time, "the need to obtain a quality education requires from children to exert internal resources and energy for intensive educational activities" [1,2]. Based on this, the study of adaptive capabilities and personality traits in adolescence and preadult age is very topical.The purpose of the study is to study the student's psychophysiological characteristics, which determine the success of passing the unified state exam.

\footnotetext{
*Corresponding author: gubareva@mail.ru
} 


\section{Subject and Methods}

The study was conducted on the basis of the SEL "Environmental Psychophysiology" of the NCFU in accordance with the requirements of biomedical ethics and the Helsinki Declaration of Human Rights. Under the conditions of a natural experiment longitudinallytransverse method, 102 schoolchildren (53 boys and 49 girls) of the 9-11th classes of secondary school No. 2 of Stavropol, without genetic pathology, were examined.

Table 1. Study design

\begin{tabular}{|l|l|l|l|}
\hline \multirow{2}{*}{ Year of research } & \multicolumn{3}{|c|}{ Number of schoolchildren } \\
\cline { 2 - 4 } & 9 th class & 10th class & 11 th class \\
\hline 2016 & 39 & 25 & \\
\hline 2017 & & 25 & 20 \\
\hline 2018 & & & 18 \\
\hline
\end{tabular}

Thus, schoolchildren of $9^{\text {th }}$ class a 3-year longitudinal research, and schoolchildren of $10^{\text {th }}$ class passed a 2-year-longitudinal research. Peculiarities of the functioning of the central nervous system (CNS) were determine by the method of computer chronoreflexometry on a psychophysiological testing device UPFT-1/30 "Psychophysiologist" (manufactured and verified by specialists of Medicom, Taganrog). Psychological testing was carried out using the C. Spielberger methods for identifying personality and situational anxiety and the "Buss-Durkey Inventory". The results of the study were exposed to statistical processing on a computer using the statistical data analysis package in Microsoft Excel-2006 out using tStudent test.

\section{Results and discussion}

Personality properties include the level of aggressiveness, personality (PA) and situational (SA) anxiety. "Each person has a genetically determined level of anxiety - beneficial anxiety. The level of anxiety is also an indicator of individual sensitivity to stress" [3]. The analysis of the results of testing the level of PA at the students of the 9-11th classes of secondary school of the city of Stavropol (Fig. 1) showed that girls and young women have a higher level of PA than boys and young men $(p<0.05-0.01)$. During the training in the girls' and boys' level of PA remains relatively constant, however, the variability of PA of 17 years-old young women is higher than of the young men. So, for girls, the variability of PA is $12 \div 63$ points (from low level $-25 \%$ of girls to high $-50 \%$ of girls), and for boys it is in narrower values $22 \div 59$ points, varying from low ( $80 \%$ of boys) to high ( $20 \%$ of boys) values. Analysis of the results of testing the level of SA of students in the 9-11th classes (Fig. 1) showed that girls and young women have a higher level of SA than boys and young men $(\mathrm{p}<0.05-0.01)$. Moreover, in the course of training, the girls' level of SA tends to increase throughout the entire period of education in secondary school, while the boys one increases only in the 10th class, and decreases by the beginning of the $11^{\text {th }}$ class. No significantly identified age differences were found. 

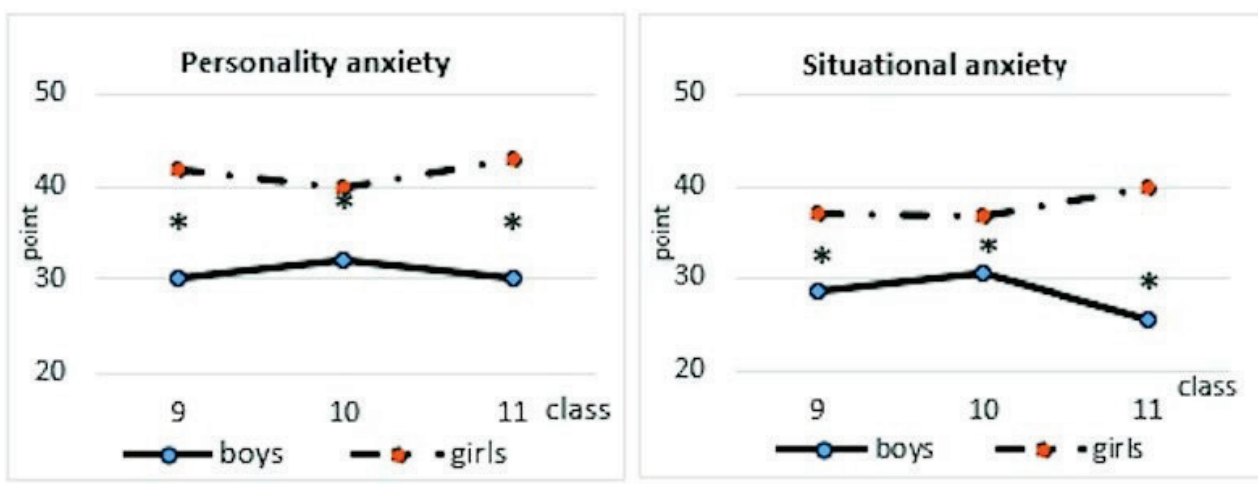

Fig. 1. Indicators of personality and situational anxiety for schoolchildren to the $9-11^{\text {th }}$ classes. Note: ${ }^{*}$ - reliability of sex differences.

The analysis of the results of the study of the level of aggressiveness of students of the 9$11^{\text {th }}$ classes, who take the SFC, showed that gender differences in aggression indicators begin to appear in the $10^{\text {th }}$ class (Table 2). So, the boys' aggressiveness index (IA) is significantly higher than the girls' $(18.3 \pm 1.2 \mathrm{p}$. and $14.0 \pm 1.5 \mathrm{p}$., respectively, $\mathrm{p}<0.05)$. In this case, the most pronounced gender differences on the scales of aggression were found by indicators of indirect aggression: in the boys' indirect aggression is higher than the girls' $(6.5 \pm 0.6$ p. and $4.6 \pm 0.5$ p., respectively, $\mathrm{p}<0,05)$.

Table 2. Indicators of aggressiveness $(\mathrm{M} \pm \mathrm{m})$ for schoolchildren to the $9-11^{\text {th }}$ classes, passing the USE (group mean values)

\begin{tabular}{|c|c|c|c|c|c|c|c|c|c|}
\hline \multirow[t]{2}{*}{ Indicators } & \multicolumn{2}{|c|}{$\begin{array}{l}9 \text { class } \\
(\mathrm{n}=39)\end{array}$} & \multirow[t]{2}{*}{$\mathrm{P}_{2}$} & \multicolumn{2}{|c|}{$\begin{array}{l}10 \text { class } \\
(\mathrm{n}=50)\end{array}$} & \multirow[t]{2}{*}{$\mathrm{P}_{2}$} & \multicolumn{2}{|c|}{$\begin{array}{c}11 \text { class } \\
(\mathrm{n}=38)\end{array}$} & \multirow[t]{2}{*}{$\mathrm{P}_{2}$} \\
\hline & $\mathrm{M}$ & $\mathrm{W}$ & & $\mathrm{M}$ & W & & $\mathrm{M}$ & W & \\
\hline $\begin{array}{l}\text { 1. Physical } \\
\text { aggression, } \\
\text { point }\end{array}$ & $5,8 \pm 0,7$ & $6,5 \pm 0,5$ & $>0,5$ & $5,9 \pm 0,7$ & $4,5 \pm 0,5$ & $>0,05$ & $6,0 \pm 0,8$ & $5,1 \pm 0,4$ & $>0,1$ \\
\hline $\mathrm{P}_{1}$ & & & & $>0,5$ & $<0,05$ & & $>0,5$ & $<0,05$ & \\
\hline $\begin{array}{l}\text { 2. Indirect } \\
\text { aggre-ssion, } \\
\text { point }\end{array}$ & $5,5 \pm 0,4$ & $5,6 \pm 0,5$ & $>0,5$ & $6,5 \pm 0,6$ & $4,6 \pm 0,5$ & $<0,05$ & $5,7 \pm 0,6$ & $4,7 \pm 0,5$ & $>0,05$ \\
\hline $\mathrm{P}_{1}$ & & & & $>0,05$ & $>0,05$ & & $>0,5$ & $>0,05$ & \\
\hline $\begin{array}{l}\text { 3. Irritability, } \\
\text { point }\end{array}$ & $6,0 \pm 0,5$ & $6,2 \pm 0,7$ & $>0,5$ & $5,9 \pm 0,6$ & $4,5 \pm 0,5$ & $>0,05$ & $5,5 \pm 0,5$ & $6,8 \pm 0,6$ & $>0,05$ \\
\hline $\mathrm{P}_{1}$ & & & & $>0,5$ & $<0,05$ & & $>0,5$ & $>0,5$ & \\
\hline $\begin{array}{l}\text { 4. Negativism, } \\
\text { point }\end{array}$ & $3,4 \pm 0,4$ & $3,2 \pm 0,3$ & $>0,5$ & $3,5 \pm 0,3$ & $3,5 \pm 0,3$ & $>0,5$ & $2,8 \pm 0,3$ & $2,6 \pm 0,3$ & $>0,5$ \\
\hline $\mathrm{P}_{1}$ & & & & $>0,5$ & $>0,5$ & & $>0,1$ & $>0,05$ & \\
\hline $\begin{array}{l}\text { 5. Offence, } \\
\text { point }\end{array}$ & $4,5 \pm 0,4$ & $4,3 \pm 0,4$ & $>0,5$ & $4,6 \pm 0,4$ & $4,75 \pm 0,5$ & $>0,5$ & $5,1 \pm 0,5$ & $3,3 \pm 0,3$ & $<0,05$ \\
\hline $\mathrm{P}_{1}$ & & & & $>0,5$ & $>0,5$ & & $>0,1$ & $\leq 0,05$ & \\
\hline $\begin{array}{l}\text { 6. Suspicion, } \\
\text { point }\end{array}$ & $5,1 \pm 0,5$ & $5,3 \pm 0,5$ & $>0,5$ & $5,2 \pm 0,5$ & $4,4 \pm 0,4$ & $>0,05$ & $5,1 \pm 0,6$ & $4,0 \pm 0,4$ & $>0,05$ \\
\hline $\mathrm{P}_{1}$ & & & & $>0,5$ & $>0,05$ & & $>0,5$ & $<0,05$ & \\
\hline $\begin{array}{l}\text { 7. Verbal } \\
\text { aggres-sion, } \\
\text { point }\end{array}$ & $6,0 \pm 0,6$ & $6,3 \pm 0,6$ & $>0,5$ & $6,4 \pm 0,6$ & $5,25 \pm 0,5$ & $>0,05$ & $7,6 \pm 0,5$ & $4,6 \pm 0,4$ & $<0,01$ \\
\hline $\mathrm{P}_{1}$ & & & & $>0,5$ & $>0,05$ & & $<0,05$ & $<0,05$ & \\
\hline
\end{tabular}




\begin{tabular}{|c|c|c|c|c|c|c|c|c|c|}
\hline $\begin{array}{l}\text { 8. Guilt } \\
\text { feeling, } \\
\text { point }\end{array}$ & $4,3 \pm 0,3$ & $5,0 \pm 0,5$ & $>0,1$ & $5,1 \pm 0,5$ & $4,7 \pm 0,5$ & $>0,5$ & $5,3 \pm 0,4$ & $5,0 \pm 0,5$ & $>0,5$ \\
\hline $\mathrm{P}_{1}$ & & & & $>0,05$ & $>0,5$ & & $\geq 0,05$ & $>0,5$ & \\
\hline $\begin{array}{c}\text { 9. Hostility } \\
\text { index, point }\end{array}$ & $9,6 \pm 0,9$ & $9,7 \pm 1,0$ & $>0,5$ & $9,8 \pm 0,8$ & $9,1 \pm 0,7$ & $>0,5$ & $10,2 \pm 1,1$ & $7,3 \pm 0,6$ & $<0,05$ \\
\hline $\mathrm{P}_{1}$ & & & & $>0,5$ & $>0,5$ & & $>0,5$ & $\leq 0,05$ & \\
\hline $\begin{array}{c}\text { 10.Aggressiven } \\
\text { ess index, } \\
\text { point }\end{array}$ & $17,8 \pm 1,2$ & $19,2 \pm 1,3$ & $>0,5$ & $18,3 \pm 1,2$ & $14,0 \pm 1,5$ & $<0,05$ & $18,8 \pm 1,1$ & $16,7 \pm 1,0$ & $>0,05$ \\
\hline $\mathrm{P}_{1}$ & & & & $>0,5$ & $<0,05$ & & $>0,5$ & $>0,05$ & \\
\hline
\end{tabular}

Note: $\mathrm{P}_{1}$ - reliability of age differences; $\mathrm{P}_{2}$ - reliability of sex differences; in parentheses the number of examined; Mo - mode; AMo - mode amplitude.

In the $11^{\text {th }}$ class, this trend persists, however, the nature of the manifestation of aggressiveness changes: the young men's the hostility indicator, which includes scales of offence and suspicion, significantly increases compared with the young women's $(10.2 \pm$ 1.2 p. and $7.3 \pm 0.6$ p., respectively, $p<0,05$ ) (Table. 1). Possibly the increase in the index of hostility and aggressiveness in some young men is due to a decrease in the resistance of the psyche to increased mental stress. At the same time, the level of frustrating emotions offence - increases, which can be regarded as a manifestation of psychoemotional stress. It should be noted that the level of verbal aggression of 17 years-old young men increases significantly compared with young women $(7.6 \pm 0.5 \mathrm{p}$. and $4.6 \pm 0.4 \mathrm{p}$., respectively, $\mathrm{p}$ $<0.01$ ) (Table 1), which, apparently, is a defensive reaction. The analysis of age-related changes by the scales of aggressiveness showed that these are manifested from the period of the transformation of a girl into a young woman and a boy into a young man (Table 1). The transformation of a girl into a young woman (the $9-10^{\text {th }}$ classes) makes her less aggressive: the level of physical aggression $(6.5 \pm 0.5 \mathrm{p}$. and $4.5 \pm 0.5 \mathrm{p}$., respectively, $\mathrm{p}$ $<0.05)$, irritability $(6.2 \pm 0.7 \mathrm{p}$. and $4.5 \pm 0.5 \mathrm{p}$., respectively, $\mathrm{p}<0.05)$ and IA $(19.2 \pm 1.3 \mathrm{p}$. and $14.0 \pm 1.5 \mathrm{p}$., respectively, $\mathrm{p}<0.05)$ in young women compared with girls decrease. The transformation of the boy into a young man (the 10-11 ${ }^{\text {th }}$ classes) makes him, apparently, more confident in the manifestation of aggression, as indicated by the preservation of the stability of most of its indicators and the tendency to a slight increase in indicators on a scale of guilt $(p>0.5)$ and decrease on a scale of negativism $(p>0.1)$. An exception is the scale of verbal aggression, which indicators for 17-year-old young man are higher than for 16-year-old boys ( $p>0.05)$. As mentioned above, an increase in the level of verbal aggression can be a manifestation of a protective reaction and self-affirmation in adulthood.

An important indicator of mental health and the level of adaptation to environmental factors is the functional state of the central nervous system (CNS) $[4,5]$. «The functional state of the central nervous system is a result of dynamic interaction with the external environment and reflects the state of an organized whole, that is of paramount importance for any activity of an adult and a child» [6]. «One of the objective criteria for the functional state of the central nervous system is the time and accuracy of the visual-motor reaction, which characterize the speed of the processes of inhibition and excitation in the central nervous system, the ability to differential inhibition and the severity of excitatory or inhibitory processes when performing sensorimotor reactions» [4]. Accounting the fact that SFC test tasks often require a non-standard approach, we tested a complex visual-motor reaction (CVMR 3) to change of the dynamic stereotype in response to a visual stimulus. In this case, two color signals were presented - red and green, to each of which the subject had to respond with a certain, pre-established movement.

According to the results of the study, gender differences were found in 
chronoreflexometry indicators, as that as in psychological indicators. In the 9th class, girls have a higher CNS excitability, judging by the number of pre-emptive stimuli, less ability to differentiate significant stimuli and alter the dynamic stereotype than boys, but more stable performance of complex visual-motor reaction 3 (CVMR 3), judging by the amplitude of the mode (AMo) of reaction time (Table 3). By the $10^{\text {th }}$ class, gender differences in the number of pre-emptive stimuli and the number of errors in differentiation are leveled, while the stability of complex reactions to the generation and modification of a dynamic stereotype is reduced. In the $11^{\text {th }}$ class, the stability of CVMR 3 performance, judging by AMo, does not significantly differ from that of young men ( $p>0.5)$. The analysis of the results of CVMR 3 in the dynamics of training (Table 3 ) revealed the following. The maximum number of missed stimuli was revealed with the boys of the $9^{\text {th }}$ class, by the $10^{\text {th }}$ class, the accuracy of CVMR 3 increases and remains stable until the $11^{\text {th }}$ class. For girls, the accuracy of performing CVMR 3 varies in small ranges of $0.10 \div 0.11$ missed stimuli, which, apparently, are the norm of the reaction, since these differences are not significant $(\mathrm{p}>0.5-0.05)$.

Table 3. Indicators of complex visual-motor reaction (CVMR 3) $(\mathrm{M} \pm \mathrm{m})$ for schoolchildren to the 9$11^{\text {th }}$ classes (group mean values)

\begin{tabular}{|c|c|c|c|c|c|c|c|c|c|}
\hline \multirow[t]{2}{*}{ Indicators } & \multicolumn{2}{|c|}{$\begin{array}{l}9 \text { class } \\
(\mathrm{n}=39)\end{array}$} & \multirow[t]{2}{*}{$\mathrm{P}_{2}$} & \multicolumn{2}{|c|}{$\begin{array}{c}10 \text { class } \\
(\mathrm{n}=25)\end{array}$} & \multirow[t]{2}{*}{$\mathrm{P}_{2}$} & \multicolumn{2}{|c|}{$\begin{array}{c}11 \text { class } \\
(\mathrm{n}=38)\end{array}$} & \multirow[t]{2}{*}{$\mathrm{P}_{2}$} \\
\hline & $\mathrm{M}$ & W & & $\mathrm{M}$ & W & & $\mathrm{M}$ & W & \\
\hline $\begin{array}{l}\text { 1. Class of } \\
\text { force of } \\
\text { inhibition } \\
\text { processes }\end{array}$ & $3,75 \pm 0,31$ & $4,10 \pm 0,30$ & $>0,1$ & $3,54 \pm 0,28$ & $3,50 \pm 0,27$ & $>0,5$ & $3,50 \pm 0,27$ & $\begin{array}{c}4,00 \pm 0 \\
, 30\end{array}$ & $>0,05$ \\
\hline $\mathrm{P}_{1}$ & & & & $>0,5$ & $>0,05$ & & $>0,5$ & & \\
\hline $\begin{array}{l}\text { 2. Number of } \\
\text { missed stimuli }\end{array}$ & $0,50 \pm 0,14$ & $0,10 \pm 0,07$ & $<0,05$ & $0,0 \pm 0,0$ & $0,0 \pm 0,0$ & $>0,5$ & $0,0 \pm 0,0$ & $\begin{array}{c}0,11 \pm 0 \\
, 08\end{array}$ & $>0,05$ \\
\hline $\mathrm{P}_{1}$ & & & & $<0,01$ & $>0,05$ & & $<0,01$ & $>0,5$ & \\
\hline $\begin{array}{l}\text { 3. Number of } \\
\text { pre-emptive } \\
\text { stimuli }\end{array}$ & $1,25 \pm 0,40$ & $4,90 \pm 1,00$ & $<0,05$ & $1,82 \pm 0,60$ & $2,67 \pm 0,40$ & $>0,5$ & $2,67 \pm 1,05$ & $\begin{array}{c}1,00 \pm 0 \\
, 45\end{array}$ & $>0,05$ \\
\hline $\mathrm{P}_{1}$ & & & & $>0,1$ & $<0,05$ & & $>0,05$ & $<0,05$ & \\
\hline $\begin{array}{l}\text { 4. Number of } \\
\text { errors in } \\
\text { differentiation }\end{array}$ & $0,0 \pm 0,0$ & $4,0 \pm 1,3$ & $<0,05$ & $0,0 \pm 0,0$ & $0,17 \pm 0,09$ & $>0,05$ & $1,17 \pm 0,09$ & $\begin{array}{c}1,00 \pm 0 \\
, 36\end{array}$ & $>0,5$ \\
\hline $\mathrm{P}_{1}$ & & & & $>0,5$ & $<0,01$ & & $<0,001$ & $<0,05$ & \\
\hline $\begin{array}{l}5 . \Sigma \text { errors } \\
\text { number }\end{array}$ & $1,75 \pm 0,51$ & $9,0 \pm 2,60$ & $<0,05$ & $1,82 \pm 0,90$ & $2,83 \pm 1,10$ & $>0,5$ & $2,83 \pm 1,00$ & $\begin{array}{c}1,50 \pm 0 \\
, 60\end{array}$ & $>0,05$ \\
\hline $\mathrm{P}_{1}$ & & & & $>0,5$ & $<0,05$ & & $>0,1$ & $<0,05$ & \\
\hline $\begin{array}{l}\text { 6. The time of } \\
\text { CVMR 3, Ms }\end{array}$ & $461,4 \pm 35,9$ & $442,3 \pm 16,2$ & $>0,5$ & $482,5 \pm 19,5$ & $450,6 \pm 20,8$ & $>0,05$ & $450,7 \pm 20,8$ & $\begin{array}{c}497,6 \pm \\
22,3\end{array}$ & $>0,05$ \\
\hline $\mathrm{P}_{1}$ & & & & $>0,5$ & $>0,5$ & & $>0,5$ & $>0,05$ & \\
\hline $\begin{array}{l}\text { 7. Standard } \\
\text { deviation of the } \\
\text { reaction time, } \\
\text { MS }\end{array}$ & $123,0 \pm 8,5$ & $122,6 \pm 13,4$ & $>0,5$ & $134,9 \pm 9,0$ & $112,5 \pm 7,2$ & $\leq 0,05$ & $112,5 \pm 7,1$ & $\begin{array}{c}193,8 \pm \\
18,9\end{array}$ & $<0,01$ \\
\hline $\mathrm{P}_{1}$ & & & & $>0,5$ & $>0,5$ & & $>0,1$ & $<0,05$ & \\
\hline $\begin{array}{l}8 . \text { Mo of the } \\
\text { reaction time, } \\
\text { MS }\end{array}$ & $435,0 \pm 30,7$ & $372,0 \pm 22,2$ & $>0,05$ & $441,8 \pm 19,6$ & $466,7 \pm 11$, & $>0,1$ & $442,2 \pm 41,0$ & $\begin{array}{c}464,4 \pm \\
19,9\end{array}$ & $>0,5$ \\
\hline $\mathrm{P}_{1}$ & & & & $>0,5$ & $<0,05$ & & $>0,5$ & $<0,05$ & \\
\hline $\begin{array}{l}\text { 9. AMo of the } \\
\text { reaction time, } \\
\%\end{array}$ & $26,6 \pm 2,2$ & $38,0 \pm 5,0$ & $<0,05$ & $27,7 \pm 1,1$ & $22,0 \pm 1,0$ & $<0,01$ & $26,2 \pm 1,7$ & $\begin{array}{c}25,8 \pm 1 \\
, 5\end{array}$ & $>0,5$ \\
\hline $\mathrm{P}_{1}$ & & & & $>0,5$ & $<0,05$ & & $>0,5$ & $<0,05$ & \\
\hline
\end{tabular}




\begin{tabular}{|c|c|c|c|c|c|c|c|c|}
\hline $\begin{array}{l}\text { 10.Maximal } \\
\text { reaction time, } \\
\text { MS }\end{array}$ & $819,0 \pm 74,3$ & $714,1 \pm 50,0>0,05$ & $870,0 \pm 48,1$ & $734,0 \pm 58,0$ & $p>0,0$ & $\begin{array}{c}993,5 \pm 131 \\
0\end{array}$ & $1, \begin{array}{c}882,0 \pm \\
65,0\end{array}$ & $>0$ \\
\hline $\mathrm{P}_{1}$ & & & $>0,5$ & $>0,5$ & & $>0,05$ & $<0,05$ & \\
\hline
\end{tabular}

Note: $\mathrm{P}_{1}$ - reliability of age differences; $\mathrm{P}_{2}$ - reliability of sex differences; in parentheses the number of examined; Mo - mode; AMo - mode amplitude.

On the contrary, the number of pre-emptive stimuli, indicating the predominance of excitation processes over inhibition processes, has maximum values in girls of the $9^{\text {th }}$ class, gradually decreasing to the $11^{\text {th }}$ class. For boys, this indicator has the opposite age dynamics, which, possible, is due to the growth of the social significance of the USE results, it a decision to continue education in the $10-11^{\text {th }}$ classes is made. At the same time, for boys by the $11^{\text {th }}$ class, the number of errors per differentiation increases significantly (Table 2), which is quite natural, since the ability to differentiate stimuli of similar quality need the prevailing inhibition processes, over excitation processes.

The time of CVMR 3 for boys and girls under 16 years old has similar age dynamics, and from 16 to 17 years old it is diametrically opposite: it decreases for boys and increases for girls (Table 2). AMo of the time of CVMR 3 for girls has maximum values in the 9th class, significantly decreasing in the 10th class, and again rising to the optimal values in the 11 th class. For boys, AMo does not change significantly during the 9-11th classes and variesbetween $27.7-25.8 \%$. In too time for girls of the 11 th class, the level of adaptive capabilities of the central nervous system is significantly higher than in boys, judging by the indicators of the standard deviation of the reaction time $(193.8 \pm 18.9 \mathrm{~ms}$ and $112.5 \pm$ $7.1 \mathrm{~ms}$, respectively, $\mathrm{p}<0.01$ ) (Table. 3).

Thus, the results of psychological testing are consistent with chronoreflexometry when performing a complex visual-motor reaction to alter the stereotype. In the $9^{\text {th }}$ class girls have a higher CNS excitability than boys, and less ability to differentiate of stimuli and alter the dynamic stereotype. By the $10^{\text {th }}$ class, gender differences in the number of preemptive stimuli and errors in differentiation are leveled. The stability of CVMR in altering the stereotype for girls is reached at 16 years old, for boys - at 17 years old, while the adaptive capabilities of 17-year-old schoolgirls are higher than their peers. An analysis of the results of USE showed that the success markers for USE passing are: the time of a complex visual-motor reaction during the remodeling of a dynamic stereotype, the level of stability of the central nervous system, the standard deviation of SVMR 3 time, mode of the time reaction, mode amplitude; the level of personality and situational anxiety, physical and verbal aggression, irritability, offence, hostility and aggressiveness index..

\section{References}

1. A.T. Zulkarnaeva, E.A. Povargo, T.R. Zulkarnaev, L.B. Ovsyannikova, A.I. Agafonov, Population Health and Habitat, 8, 29-31 (2012)

2.E.A. Lapteva, V.B. Lyubovtsev, L.M. Mamalyga, Fundamental research, 7-3, 575-579 (2013)

3.E.I. Rogov, Handbook of a Practical Psychologist. T.2. (Vlados, Moscow, 1998)

4.L.I. Gubareva, Ecological stress. Monograph (Vlados - Stavropol: Stavropolservischool, St. Petersburg, 2001)

5.M.M. Bezrukikh, V.D. Sonkin, D.A. Farber, Age physiology, physiology of child development (Academy, Moscow, 2002)

6.P.K. Anokhin, Nodal questions of the theory of functional systems (Nauka, Moscow, 1980) 